\title{
La escritura del vacío: exilio, enigma y memoria en Paul Celan y Edmond Jabès
}

\author{
Luis MARTÍNEZ-FALERO \\ Departamento de Lengua Española y Teoría de la Literatura y Literatura Comparada \\ Universidad Complutense de Madrid \\ lmartinezfalero@fillol.ucm.es
}

\section{RESUMEN}

En este trabajo se plantea un estudio de literatura comparada sobre la poesía de Edmond Jabès y de Paul Celan. En ambos autores hallamos puntos formales (el empleo del aforismo, por ejemplo) y, en ocasiones, temáticos comunes, así como un planteamiento de la palabra poética como palabra trascendente. Pero existe, en torno al exilio y al desarraigo, un planteamiento distinto: Jabès enlaza con la tradición profética y de los salmos, mientras que Celan busca un lenguaje poético que exprese el horror de los campos de exterminio. Así, se enfrentan la palabra profética (dar la palabra a quien no la tiene y dar nombres al innombrable) a un lenguaje que supere al lenguaje, que rompa sus estructuras, sin romper su conexión con el referente del exterminio judío. De este modo, desde un punto inicial de coincidencia se alcanzan las posibilidades temáticas y formales derivadas de estas dos poéticas.

Palabras clave: poesía europea, literatura comparada, imaginario judío, exilio, holocausto.

The writings of emptiness: exile, enigma and memory in Paul Celan and Edmond Jabès

\begin{abstract}
This paper proposes a study in comparative literature on the poetry of Edmond Jabès and Paul Celan. In both authors we can find common formal points (as aphorisms, i. e.) and, sometimes, themes, as well as the understanding of the poetic word as a transcendent one. But, regarding exile and uprootness, a different point of view: Jabès relates to the prophetic tradition and the psalms, meanwhile Celan searches for a poetic language able to express the horror of the death camps. The prophetic word (to give word to whom has not and to give name to the unnamable) is confronted to a language that surpasses language, that breaks its structures, without breaking its connection to the Jewish annihilation referent. This way, from a coincidental starting point the thematic and formal possibilities of these two poetics are reached.
\end{abstract}

Key words: European poetry, comparative literature, Jewish imaginary, exile, holocaust. 
"J'ai quitté une terre qui n'etait pas la mienne, / pour une autre qui, non plus, ne l'est pas. / Je me suis réfugié dans un vocable d'encre, / ayant le livre pour espace..." (Jabès 1989: 107). El exilio conlleva el desarraigo, la pérdida de las coordenadas existenciales que marcan el territorio del ser humano, que es trasladado a un territorio ajeno o a unas coordenadas distintas (geográficas, culturales...) que le llevan a ser otro, un extranjero (cuya etimología lo identifica con 'extraño') incluso en su país. Así, Claudio Guillén nos dice:

El yo siente como rota y fragmentada su propia naturaleza psicosocial y su participación en los sistemas de signos en que descansa la vida cotidiana. Es la crisis que vivió Ovidio, y siglos después, tantos otros, como sobre todo el moderno poeta o intelectual exiliado sin salir de su país. (Guillén 1998: 30)

En el caso de España, los ejemplos más evidentes del exilio interior serían Vicente Aleixandre o Antonio Gamoneda, al margen de la cultura oficial durante muchos años y en los que lo político desempeñó -en ambos casos- un importante papel para permanecer en la penumbra de una España de persecuciones y de miseria no sólo económica, sino, sobre todo, de la aún más profunda miseria moral.

Persecución y miseria moral de sendos totalitarismos son también los elementos biográficos que conducen a Edmond Jabès y a Paul Celan a París, en periodos y por motivos distintos. Jabès, egipcio de religión judía, fue expulsado por Nasser en el año 1956 y residió en Francia, pues se había formado en la cultura francesa y había mantenido una intensa relación epistolar con poetas franceses como René Char o con el crítico Gabriel Bounoure. Por su parte, Celan, judío rumano de lengua alemana, perdió a sus padres en el campo de concentración ucraniano de Michailowka (él mismo estuvo en un campo de trabajo) y, tras la Segunda Guerra Mundial, sufrió la división de su región natal (la Bucovina) entre Rumanía y Ucrania. Celan, apátrida y judío, acabó su periplo europeo también en París. En ambos casos, el exilio y el pasado ocupan un lugar esencial en las respectivas poéticas, que parten del imaginario judío, si bien, como veremos, presentan notables diferencias.

\section{EDMOND JABÈS: EL DESIERTO Y LA PALABRA ERRANTE}

La voz que clama en el desierto es la voz del profeta, pero es también la voz del poeta, impulsado por el silencio del eterno ausente, del Dios sin nombre (YHWH) que necesita de la palabra de los hombres para hacerse presente. Así, en la producción poética de Edmond Jabès retornamos al concepto de poeta como profeta, al terreno de la poesía como revelación y escucha, situada en el desierto, principio y fin de todos los caminos, principio y fin de la palabra. Como señala Maurice Blanchot: "La palabra profética es una palabra errante que retorna a la exigencia originaria de un movimiento, oponiéndose a toda estancia, a toda fijación, a un enraizamiento que fuese reposo" (Blanchot 2005: 106), pero que se transfiere a la poesía, por ejemplo, en la obra de Mallarmé (Blanchot 1992: 45-50). De este modo, la poética jabèsiana se asienta sobre una concepción de la palabra errante, identificando 
poeta y judío, en tanto que ambos carecen de una patria concreta: su único territorio, su única identidad, es la palabra, la revelación de una trascendencia cuyo verbo adquiere el carácter de territorio mítico.

En esta concepción de la poesía, el poeta de origen egipcio asume -por una parte- esa idea de escucha mística (la suspensión del sentido, en espera de la revelación divina, mediante la introspección), pero trasladada a la creatividad, trasformada en ante-palabra, en el silencio previo y cargado de sentido anterior a la escritura, pero que es ya palabra en germen, manifestación inicial de una palabra trascendente:

Comment s'effectue le passage du silence à l'écrit ? Un tremblement de l'écriture, parfois, le révèle; ce tremblement est provoqué par l'écoute, l'ultime et immémoriale écoute qui fait, quelque part, basculer la langue et la pensée. Mais le miracle est que la langue, loin d'être entamée, s'en trouve enrichie. (Jabès 2003: 11)

Por otra parte, al tratarse de una palabra trascendente, Jabès se sirve de procedimientos creativos propios del imaginario judío, al emplear el aforismo y el diálogo, actantes pertenecientes al midrash o exégesis de la Torah, si bien en la obra de este poeta se trata de rabinos ficticios, que debaten, no sobre el sentido de la Escritura, sino sobre el estatus del ser humano en el mundo, la escritura como manifestación de su naturaleza y sobre el ser judío. Pero Jabès no busca una revelación divina, sino una revelación de lo humano, por lo que su poesía siempre traza vías relativas de acercamiento a lo trascendente, caminos que se borran y resurgen como las rutas del desierto, por lo que cada libro parece nacer como un escolio respecto de una idea central (el exilio del poeta en el mundo), donde radica la cuestión central de su producción, puesto que, a partir de esa encrucijada, se va a ir formando una idea de divinidad que de otro modo sería imposible, ante la ausencia de cualquier otra manifestación:

Les livres jabésiens seraient plutôt de suites de scolies qui se ramifient sous forme aphoristique pour former un réseau de paroles engedrant à un moment donné le résultat recherché : une verité toute relative, ratachée et soutenue par les propos qui la portent et qui lui donnent sa valeur, c'est-à-dire sa force. La divinité des paroles n'est pas donnée, et si Jabès veut utilisser expressément cette terminologie c'est pour montrer que la divinité est à inventer [...] elle ne peut reposer que sur les vocables. (Fernández Zoila 1978: 113)

Es aquí, al tratar la escritura, donde Jabès asume la cuestión sobre el Libro (lugar de la revelación), propuesta por Mallarmé en Igitur y que el poeta egipcio desarrolla como base de su obra, identificando obra y desierto (Martínez-Falero 2009). Si habíamos asumido en Jabès la idea del desierto como lugar de lugares, el concepto de Libro (imagen del desierto) debe asumirse como lugar de confluencia de los libros, como conjunto de las obras particulares que trazan un haz potencialmente infinito de trayectorias (lecturas), al aparecer formando bloques homogéneos mediante ciclos: Le Livre des questions (1963-1973), Le Livre des ressemblances (1976-1980), Le livre des marges (1975-1991); y mediante la inserción de poemas o secciones enteras de unos libros en otros, incluso traspasando las fronteras textua- 
les marcadas por cada ciclo e integrando breves citas, textos, secciones o temas en libros exentos, como Le petit livre de la subversion hors de soupçon (1982), Le livre du partage (1987), Un étranger avec, sous le bras, un livre de petit format (1989) o Le livre de l'hospitalité (1991), que quizá quedan como márgenes de estos ciclos sucesivos, aunque, en ocasiones, integran elementos o desarrollan motivos de otros libros. Esta idea de Libro la formuló Jabès de la siguiente manera:

De hecho, en el momento de comenzar un libro -y sin duda no sea el único-, me encuentro literalmente sumergido por su materia. Es como si una multitud de posibles libros esperasen ver la luz.

Quizás, esta materia sea el "libro absoluto", aquél en el que se fundieran todos los libros de los que fuésemos capaces. Ésta no es, en verdad, más que un vasto rumor ininteligible, al no ser formulable pero que, al menos, parece poder serlo. (Jabès 2000: 65-66)

Este proyecto de Libro, formado por los libros de cada ciclo y los libros exentos, se materializa en poemas que desarrollan la perspectiva sobre esta idea central de la poética jabèsiana (procedente de Mallarmé), concibiendo el libro (como parte o tesela del Libro) como punto de encuentro, es decir, como palabra compartida que nos une a todos como extranjeros que permanecen conectados entre sí por ese verbo trascendente que habla de nuestro estar-ahí, de nuestro ser en el mundo:

Aurore, immense désir du livre.

Savions-nous, ô fatalité, que l'eblouissant matin de l'écriture n'était, désert de cendres, que mirage d'au-delà, où le feu est à son zénith ?

«Le livre du partage, disait-il, n'est peut-être, que le livre d'une espérance partagée des mots dont l'aubre et le crépuscule -ô clarté de toute clé- furent l'éveil et le terme».

De l'ardeur d'un premier feu au défigu-rement d'un feu agonisant, nous aurons, avec des mots luisants, borné l'abîme. (Jabès 1987: 142-143)

La palabra cobra así trascendencia, inagotada en su sentido, escrita al margen, como abismo y límite a la vez, pero fuera del tiempo, alcanzando la trascendencia humana por el estatismo de la palabra escrita, errante y abierta, pues su dinamismo es sólo virtual. El margen es el espacio del silencio. La palabra queda, de este modo, determinada no sólo por lo que dice, sino por lo que calla, por lo que oculta, pero que queda latente en su sonido, evocado en la escritura. Entre palabra y silencio sólo queda el espacio de la obsesión de ese sonido que retorna, de ese sentido que se pretende alcanzar:

(Le verbe n'est pas le commencement mais la limite. Il est le terme antérieur, l'accession au fatal péril que l'homme acceptera de courir.

Commencement et fin de l'écrit ne sont que dérangeante obsession du mot, sa fausse mobilité.) (Jabès 1984: 22) 
El judío es el poseedor de esa palabra, el que atiende esa palabra también como actividad ética, social, al compartirla (Levinas 2006: 57-76; Blanchot 2006: 635636): el poeta también lo es (recordemos esa identificación establecida por Jabès entre ambos). Por ello, el poeta pasa a identificarse con el extranjero, con el exiliado de un mundo que no le pertenece, de acuerdo con el arquetipo de "L'albatros" creado por Baudelaire. En el caso de Jabès, el extranjero es aquél que busca una palabra definitiva (procedente del Libro), trascendente, pero aquí se traslada esa idea de palabra como territorio desde el terreno religioso al profano, para fundamentar esa trascendencia humana. El extranjero es, por tanto, aquél que busca esa palabra. Maurice Blanchot nos habla del origen de este recorrido en los siguientes términos:

Hay un nivel en el que el problema de lo ajeno [l'étranger] es el del hombre, el del extranjero -tal hombre, tal individuo- que se siente "extranjero en la tierra". Se trata entonces de un antiquísimo tema religioso. Secularizado, es un tema romántico: el extranjero romántico es "un soñador de otros mundos" que piensa que ninguna parte conduce a alguna parte. (Blanchot 2001: 84)

En Un étranger avec, sous le bras, un livre de petit format Jabès afrontó la cuestión del exilio y del extranjero en todas sus vertientes. Si en el ciclo de libros que conforma el Livre des questions había tratado el tema de la Soah de un modo superficial (lo que provocó el rechazo de algunos pasajes por parte de Paul Celan), en este libro alcanzó un mayor grado de exactitud al tratar un tema que formaba parte de su propia biografia. Es cierto que existe asimismo un alto grado de idealización, tal vez necesario para que su testimonio pueda ser leído con la universalidad que pretende alcanzar toda poesía escrita como reflexión (impulsada por las imágenes) que busca perdurar en el tiempo, más allá de la anécdota particular y contingente. Por ello, en Un étranger avec, sous le bras... Jabès parece indicarnos que en el extranjero reside la palabra (y la luz de esa palabra), mientras que nos acosa la muerte como expresión del vacío:

«L'étranger est celui qui vient.

«Il est, toujours, celui qui va venir.

«L'irrepérable premier rayon solaire. Nul ne

l'aura perçu.

«Le jour le noie. La nuit le nie.

«Il aura vécu, un court instant, de soi-même.

«Le ciel, pourtant, lui doit sa luminosité»,

disait-il.

Un sage disait: «Toute naissance est offense au silence; la mort, solennelle soumission.» (Jabès 1989: 68-69)

A través de este concepto de exilio, Jabès relaciona los poemas contenidos en este libro con Le livre des ressemblances (1976) ${ }^{1}$, donde el diálogo de rabinos ficticios define y delimita el exilio mediante aforismos; por ejemplo:

\footnotetext{
${ }^{1}$ Este es el libro central del ciclo al que da nombre, formado por Le livre des ressemblances (1976), Le soupçon. Le desert (1978) y L'inneffaçable. L'inaperçu (1980). 
«L'exil et la mort ont même dépendence; car la mort est nuit de l'exil et l'exil, jour de mort», disait reb Nataf.

«Nous triompherons dans l'exil. Ainsi fit Dieu», avait écrit reb Safra dont on ne retrouva jamais le corps après sa mort et dont il est raconté que son âme avait acquis une telle transparence, qu'une fois parmi ses sœurs, elle ne fut d'aucune remarquée. (Jabès 1978: 78)

Pero en Un étranger avec, sous le bras... este tema crucial en la obra de Jabès se ve unido al de la palabra y la escucha, con el silencio como forma del sentido, con el desierto como lugar de la palabra, lugar en blanco que espera la escritura:

-Il n'y a pas d'histoire de la parole mais, inaltérable, une histoire du silence. La parole la ressasse pour nous.

-Nous ne connaisons, du silence, que ce que la parole peut nous en dire. Que tu le veuilles ou non, c'est la parole seule que nous entérinons.

-Lorsque tu lis, à voix haute, un texte, n'est-ce pas ta voix que tu entends ? L'histoire du silence est un texte.

L'écoute du silence, un livre.

L'instant dit. La durée est dite. La durée est absence et l'instant, trace relevée d'une absence révélée à soi-même. [...]

Au commencement était le livre à son blanc commencement. (Jabès 1989: 67)

Si en estos libros, desarrollados mediante poemas en prosa y versículos, con un marcado carácter aforístico, Jabès desarrolla los caminos paralelos y convergentes entre palabra y silencio, margen y caudal de la palabra poética, conformando el espacio de la escritura, es en su obra lírica donde se manifiesta de manera más gráfica esa interconexión entre ambos. El silencio da sentido a la palabra, así como el blanco supone el espacio que da sentido a la escritura, de acuerdo con Mallarmé, quien reflexiona sobre él en varios pasajes de sus Divagations y que lo convierte en presencia significativa en "Un coup de dés", única parte de Igitur plenamente desarrollada. En el libro de Jabès Récit (1980) hallamos "La mémoire et la main" (segmento escrito entre 1974 y 1980), donde esos márgenes quedan delimitados al máximo; así,

L'univers traverse la main, verse dans

l'abîme

Les horizons sont privés d'air, les extrêmes. (Jabès 2003: 368)

De este modo, se abre la posibilidad de una poesía del silencio como expresión máxima de la escritura, donde la luz de la palabra abrasa la página hasta devolverla a su blancura inicial, hasta la memoria inicial, borrando así la historia, transformada en palabra que sustituye a la memoria:

«Comment lire une page déjà brûlée, dans un livre qui brûle, sinon en faisant appel à la mémoire du feu», disait un sage. 
Il dissait aussi : «La trace laissée par un livre n'est, peut-être, qu'une tenace odeur d'instants brûlés». (Jabès 1987: 136)

También en Bonnefoy o Gamoneda el territorio abrasado de la historia se hace palabra, recoge la memoria para transformarla en una nueva identidad en la palabra. El poeta francés nos dice:

Les livres, ce qu'il déchira,

La page dévastée, mais la lumière

Sur la page, l'accroissement de la lumière,

Il comprit qu'il redevenait la page blanche [...]. (Bonnefoy 2006: 39)

Escritura en el silencio y del silencio, palabra errante que queda fijada en un desierto, donde los sonidos, como las dunas, varían su dirección hasta trazar los nuevos caminos del hombre con las palabras del hombre, para dar forma al eterno ausente; exilio, al fin y al cabo, del judío y del poeta.

\section{PAUL CELAN Y LA MEMORIA DEL HORROR}

Para hablar de la visión del exilio en la obra poética de Paul Celan es necesario partir de la conocida cuestión suscitada por Th. Adorno en Prismas (1955): ¿Es posible la poesía después de Auschwitz? Conocemos, por repetida, la respuesta del filósofo de la Escuela de Frankfurt: "Nach Auschwitz ein Gedicht zu schreiben, ist barbarisch" (tras el horror de los campos de exterminio, cualquier manifestación lírica es un acto de barbarie) (Adorno 1962: 11). Sin embargo, también sabemos que Adorno modificó posteriormente su sentencia en su Dialéctica negativa (1966), tras la lectura de la poesía de Celan. Pero para superar el horror, para combatir la barbarie, era necesario un lenguaje nuevo, un lenguaje más allá del lenguaje, que llevara hasta el límite las posibilidades expresivas del idioma, para mostrar la memoria de una tragedia personal marcada por la muerte de sus padres en el campo ucraniano de Michailowka y el exilio del poeta, sólo superados con el salto al vacío desde el Pont Mirabeau.

Ciertamente, Celan no es el único (ni siquiera en la poesía alemana) que habla del horror de la Shoah y del exilio. Así, su amiga Nelly Sachs, con quien mantuvo una intensa relación epistolar, también se refiere a la Shoah, desde su exilio sueco, iniciado en 1940 y del que nunca regresó. Nelly Sachs optó por la reescritura de arquetipos míticos y simbólicos de la Torah (incluyendo los elementos que componen el Zohar), en una búsqueda de las causas del horror y en una constante interrogación por el silencio de un Dios innominado y ausente ante el sufrimiento de su pueblo, como en este poema de Sternverdunkelung (Eclipse estelar, 1949):

\section{JACOB}

O ISRAEL,

Erstling im Morgengrauenkampf

wo alle Geburt mit Blut 
auf der Dämmerung geschrieben steht.

$\mathrm{O}$ das spitze Messer des Hahnenschreis

der Menschheit ins Herr gestochen,

o die Wunde zwischen Nacht und Tag

die unser Wohnort ist!

Vorkämpfer,

im kreißenden Fleisch der Gestirne

in der Nachtwavchentrauer

daraus ein Vogellied weint.

O Israel,

du einmal zur Seligkeit endlich Entbundener-

des Morgentaus tröpfelnde Gnade

auf deinem Haupt -

Seliger für uns,

die in Vergenssenheit Verkauften,

ächzend im Treibeis

von Tod und Auferstehung

und vom schwerem Engel über uns

zu Gott verrenkt

wie du! (Sachs 2009: 110-111)

Frente a esta reescritura efectuada por Nelly Sachs, Paul Celan ofrece una escritura más radical, partiendo desde el jasidismo, cuyas enseñanzas se transmitían a través de aforismos y secuencias rimadas (Scholem 2000: 352; Laenen 2006: 253260), hasta alcanzar la ruptura de la forma mediante un lenguaje que supera cualquier intento de comprensión inmediata. Su testimonio del horror sólo pudo comunicarse mediante un lenguaje que escapa al lenguaje, que rompe la sintaxis, que alcanza en muchas ocasiones el grado de lo inhumano ${ }^{3}$. Porque el horror no fue sólo un horror localizado en un momento dado de la sociedad europea, sino que se trataba de la culminación de un horror histórico, que había conocido determinados hechos que presagiaban ya su advenimiento, como sucede con el asesinato de Rosa Luxemburgo, descrito en el siguiente poema, perteneciente a Schneepart (Parte de nieve, 1971):

DU LIEGST im großen Gelausche, umbrucht, umflockt.

2 "JACOB // OH ISRAEL, / primogénito en la lucha del alba / donde todo nacimiento con sangre / está escrito en el crepúsculo. / ¡Oh el cuchillo afilado del canto del gallo / clavado en el corazón de la humanidad, / oh la herida entre noche y día / que es nuestro lugar de residencia! // Paladín, / en la carne parturienta de las estrellas, / en el duelo de la vela nocturna / por el que un canto de pájaro llora. // Oh Israel, / tú una vez para la bienaventuranza finalmente liberado - / del rocío de la mañana tu gracia en gotas / sobre tu cabe$\mathrm{za}-/$ ¡Bienaventurado para nosotros, / los vendidos en olvido, / gimiendo en el hielo movedizo / de muerte y resurrección / y por el pesado ángel sobre nosotros / torcidos hacia Dios / como tú! ///" (Sachs 2009: 110111).

3 Véase, en este sentido, el poema "ZRTSCH": "Zahniger Zorn, / ich zätsche, / zundere, / zaide, // Es ännt / hinterm Hirn, / es gegittert. // E-e-g! E-e-g! // Ichs haare, ich härsche. // Öötschst, Heringst///" (Celan 2003: 225). 
Geh du zur Spree, geh zur Havel, geh zu den Fleischerhaken, zu den roten Äppelstaken aus Schweden -

Es kommt der Tisch mit den Gaben, er biegt um ein Eden -

Der Mann ward zum Sieb, die Frau

mußte schwimmen, die Sau,

für sich, für keinen, für jeden -

Der Landwehrkanal wird nicht rauschen.

Nicht

stockt. (Celan 2004: 353-354)

El crimen sólo puede establecer su paralelismo con otro crimen; la sangre, con otra sangre. Por ello, Celan hace confluir el imaginario judío con el cristiano en su poesía $^{5}$, no como provocación -como pareció creer una parte de la crítica alemana (Felstiner 2002: 161)-, sino como constatación de una misma sangre fluyendo a lo largo de la Historia, hasta desembocar en el campo de concentración, como lugar no nombrado, pero evidente en los textos. El prendimiento injusto, la tortura y la muerte se repiten, hasta pedir al Dios (judío o cristiano) que ruegue por nosotros, que nos ruegue por su abandono, superando así el grado de rebeldía y desesperación que veíamos en Nelly Sachs. Así, es el ser humano el que vive una pasión continua, mientras Dios se mantiene al margen, como en el poema "Tenebrae", de Sprachgitter (Reja del lenguaje, 1959):

\section{TENEBRAE}

Nah sind wir, Herr, nahe und greifbar.

Gegriffen schon, Herr, ineinander verkrallt, als wär der Leib eines jeden von uns dein Leib, Herr.

Bete, Herr, bete $\mathrm{zu}$ uns, wir sind nah.

Windschief gingen wir hin, uns zu bücken nach Mulde und Maar.

\footnotetext{
4 "ESTÁS ECHADO en este extenso escuchar, / rodeado de espesura, de copos rodeado. // Ve tú al Spree, ve al Havel, / ve a los ganchos de carnicero / ve a las rojas manzanas en palillero / de Suecia - // Viene la mesa que las ofrendas trae, en un Edén da la vuelta - // El hombre quedó como un colador, la mujer, / la marrana, flotando se tuvo que ver, / por ella, por nadie, por cualquiera. // El canal de Landwehr no va a murmurar. // Nada queda / estancado ///" (Celan 2004: 353-354).

5 Este proceso de cruce de elementos del imaginario judío y del cristiano comenzó en su poesía de juventud: por ejemplo, el poema "Dornenkranz" (“Corona de espinas") (Celan 2010: 42).
} 
Zur Tränke gingen wir, Herr.

Es war Blut, es war,

was du vergossen, Herr.

Es glänzte.

Es warf uns dein Bild in die Augen, Herr.

Augen und Mund stehn so offen und leer, Herr.

Wir haben getrunken, Herr.

Das Blut und das Bild, das im Blut war, Herr.

Bete, Herr.

Wir sind nah. (Celan 2004: 125)

En esta unión de imaginarios (el judío y el cristiano, de fácil imbricación, por su contigüidad), la cuestión del enigma como característica formal del poema, cuyo sentido no se infiere de manera inmediata, se convierte en un elemento consustancial a la poética de Celan, que se transfiere a la de Ingeborg Bachmann ${ }^{7}$, en la poesía alemana, o a la de José Ángel Valente, en la española, no sólo en Tres lecciones de tinieblas (1980), sino en el resto de la producción posterior del poeta orensano. Tanto en el poema "Tenebrae" de Celan como en Tres lecciones de tinieblas de Valente, el origen se encuentra en las Leçons de tenèbres de François Couperin, aunque la trayectoria entre estos dos poetas es inversa: introducción de elementos del imaginario cristiano partiendo del imaginario judío en Celan; empleo del imaginario judío partiendo del imaginario cristiano en Valente. El contexto es muy distinto: Celan realiza esta imbricación de imaginarios para mostrar el horror del ser humano, mientras que Valente la lleva a cabo para reflexionar sobre la creación poética y el lenguaje.

Este enigma, que ocupa la forma de la poesía de Celan tras la Guerra Mundial ${ }^{8}$, es la única expresión posible ante lo inefable de su experiencia, por lo que, en paralelo al místico como creyente, Celan está fundando una mística de lo profundamente humano, de lo que sólo puede ser expresado por un lenguaje fragmentado y roto, "corrompido" en cuanto a la ruptura de las reglas gramaticales, pero cuya aparente corrupción no es sino una respuesta (quizá la única posible) al sinsentido de la Historia (Bollack 2003: 147-149; Forster 2009: 95-115). Lo biográfico, que supone que

\footnotetext{
6 Sigo aquí la traducción de J. Á. Valente: “Tenebrae // Estamos próximos, Señor, / próximos y apresables. / Ya apresados, Señor, / uno en otro enzarzados, como / si la carne de cada uno de nosotros fuese / tu carne, Señor. // Ora, Señor, / invócanos, / estamos próximos. // Ladeados por el viento íbamos, / caminábamos para inclinarnos / sobre la zanja y la oquedad. // Al abrevadero íbamos, Señor. / Era sangre, era / lo que tú has derramado, Señor. // Brillaba. // Nos arrojó tu imagen a los ojos, Señor. / Los ojos y las bocas tan abiertos están, tan vacíos, Señor. // Hemos bebido, Señor, / la sangre con la imagen que en ella estaba, Señor. // Ora, Señor. / Estamos próximos. ///" (Valente 2002: 272-273).

7 Jean Bollack considera como cumbre de esta influencia el poema de Ingeborg Bachmann "Los puertos estaban abiertos", cuyo cierre dice: “[...] Exterminados, permanecíamos allí. Nuestro blasón voló por los aires: // Una cruz en la sangre y un barco más grande por encima del corazón///" (Bollack 2005: 365).

${ }^{8}$ A pesar de la riqueza de imágenes de la poesía de juventud de Celan, se puede observar la creciente dificultad formal al comparar, por ejemplo, el poema que dedicó a su madre en los años treinta -"DIE MUTTER, lautlos heilend aus der Nähe..." (Celan 2010: 16)-, el escrito durante el internamiento de sus padres en Michailowka, con el apóstrofe "madre" y esa referencia a la nieve en Ucrania -"ES FÄLLT NUN, MUTTER, Schnee in der Ukranie..." (Celan 2010: 70) - y el poema "Wolfsbohne", cuando la tragedia ya se había consumado (Celan 2003: 47-50 / 310-313).
} 
la obra de Celan supere la autorreferencialidad del símbolo literario y lo fictivo-biográfico como características del lenguaje poético contemporáneo, se constituye de este modo en la base que sustenta la producción poética celaniana, estructurándola en una circularidad en cuyo centro se sitúa el dolor más profundamente humano, la consciencia del mal y el sufrimiento, más allá de lo descrito por John Milton en Paradise Lost, donde se reutilizan también arquetipos del imaginario judío, pues aquí el testimonio personal se convierte en compromiso ético ante la manifestación de esa vertiente inhumana de nuestra naturaleza y "Nadie / testimonia por el / testigo" (Celan 2004: 235). En Celan, la circularidad obsesiva nos lleva a paralelos textuales, a un número amplísimo de secuencias marcadas por las subcategorizaciones anómalas, a estructuras léxicas inusitadas en alemán y al empleo de términos cuya única interpretación posible nos conduce a unos valores sólo recuperables desde la etimología (Szondi 2005: 49-101). Para formular este universo poético, estas constelaciones de dolor y palabras se articulan en una constante concatenación de imágenes, como en el poema "Engführung", de Sprachgitter, donde todas las formas del enigma se concentran a partir de la primera estrofa, hasta desembocar, en estructura especular, en la última:

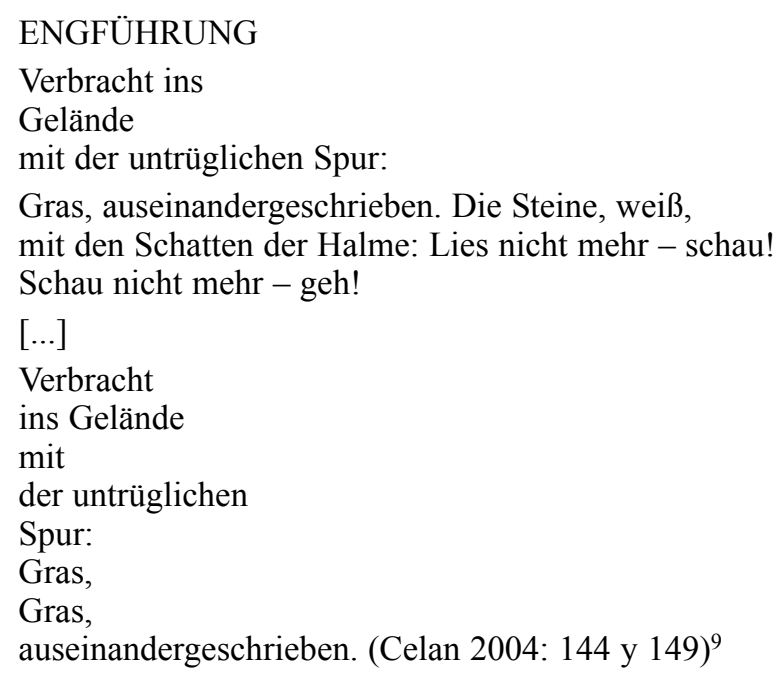

Es así, en la huella del paso de lo biográfico a lo formal y de lo formal a lo enigmático, donde la obra de Celan alcanza su verdadera unidad y sentido. Desentrañar el enigma del poema es desocultar al ser humano, como sucede también en la poesía de Georg Trak $1^{10}$, por lo que la tarea hermenéutica ante la poesía de Celan (como

\footnotetext{
9 “ANGOSTURA // Trasladado al / terreno del vestigio inequívoco: // Hierba, separadamente escrita. Las piedras, blancas, / con las sombras de los tallos: / ¡No leas más - mira! / ¡No mires más - anda! [...] Llevado / al terreno / del / vestigio / inequívoco: // Hierba. / Hierba, / separadamente escrita. ///" (Celan 2004: 144 y 149$)$.

${ }_{10}$ Resulta evidente el paralelismo de los poemas de Celan con la Shoah como tema y el poema "Grodek" de Trakl, escrito tras la batalla de ese nombre en la I Guerra Mundial.
} 
ante la de otros grandes poetas) desemboca, en realidad, en una lectura profunda de lo humano, en tanto que verdad del ser humano (Aletheia, como 'desocultación', como "sacar a la luz") (Heidegger 2002: 29-62). El poeta se ha servido de un lenguaje otro, de un lenguaje poético donde la imagen se ha hecho concepto y éste nos remite (como lectores) de nuevo a una imagen. En ese juego de referencias, en ese haz de representaciones, radica también la existencia, porque nuestra memoria (sucesión de imágenes) pasa a ser lenguaje e identidad. Pero, además, ese lenguaje otro está dirigido a sí mismo, como forma de autoconocimiento y, al tiempo, también a los demás, en una actividad ética de naturaleza comunicativa (Ricœur 1996). El otro (los lectores, el poeta) se contempla en el espejo de las palabras:

\author{
DER ANDERE \\ Tiefere Wunden als mir \\ schlug dir das Schweigen, \\ grössere Sterne \\ spinnen dich ein in das Netz ihrer Blicke, \\ weissere Asche \\ liegt auf dem Wort, dem du glaubtest. (Celan 2003: 31) ${ }^{11}$
}

El silencio es donde el sentido último de la palabra poética queda resonando, aguardando el instante en que, como un eco, una memoria (la memoria del otro) la recupere, la reconstruya desde sus cenizas, le dé la forma de la herida que la provocó, para salvarla del vacío, para salvarnos, aunque quizá sepamos que ya no hay salvación posible.

\title{
3. LA ESCRITURA DEL VACÍO: EXILIO, MEMORIA, SILENCIO
}

“¿Cómo leer una página ya quemada, en un libro que quema, sino apelando a la memoria del fuego?". En este fragmento de un poema en prosa de Jabès podemos condensar la memoria del exilio, la memoria de una ausencia. La única forma de escribir el vacío es el silencio, el trayecto de la palabra que atraviesa el lenguaje para ser imagen del vacío, territorio de una escritura que se sitúa en la paradoja de ser palabra para dar cuenta de la no-palabra. Así, los paisajes descritos (interiores y exteriores) son territorios devastados por la llama (el blanco) que hacen evocar el soporte de la escritura (esa "hierba separadamente escrita", de Celan), la página donde se materializa la memoria. Sólo este territorio del silencio da sentido a la palabra, al exilio del lenguaje como forma de comunicación, a la ausencia de un ser que sólo se hace presencia mediante la memoria de esa ausencia.

Jabès o Celan nos han servido de modelo de este exilio de una tierra natal que se ha transformado en un exilio del lenguaje. En ese exilio se ha dado forma al territo-

11 "EL OTRO // Heridas más profundas que a mí / te causó el silencio, / mayores estrellas / te urden en la red de sus miradas, / más blanca ceniza / yace en la palabra que tu creíste ///" (Celan 2003: 31). 
rio de la escritura, a la inmensidad que se ha abierto en la lectura sin fin de este vacío.

\section{BIBLIOGRAFÍA}

ADORNO, Theodor W. (1962): Prismas. La crítica de la cultura y la sociedad. Barcelona: Ariel.

BLANCHOT, Maurice (1992): El espacio literario. Barcelona: Paidós.

- (2001): "Lo extraño y el extranjero". Archipiélago, 49, pp. 80-86.

- (2005): El libro por venir. Madrid: Trotta.

- (2006): L’Entretien infini. París: Gallimard.

BOLLACK, Jean (2003): L'écrit. Une poétique dans l'œuvre de Celan. Paris: PUF.

- (2005): Poesía contra poesía. Celan y la literatura. Madrid: Trotta.

BONNEFOY, Yves (2006): Les planches courbes. París: Gallimard.

CELAN, Paul (2003): Los poemas póstumos. Edición bilingüe de José Luis Reina Palazón. Madrid: Trotta.

- (2004): Obras completas, ed. bilingüe de José Luis Reina Palazón. Madrid: Trotta.

- (2010): Poemas y prosas de juventud. Edición de Barbara Wiedemann, traducción de José Luis Reina Palazón e Ioana Zlotescu. Madrid: Trotta.

FELSTINER, John (2002): Paul Celan. Poeta, Superviviente, Judío. Madrid: Trotta.

FERNÁNDEZ ZOILA, Adolfo (1978): Le livre: recherche autre d'Edmond Jabès. Paris: Éditions Jean-Michel Place.

FOSTER, Ricardo (2009): Los hermeneutas de la noche. De Walter Benjamin a Paul Celan. Madrid: Trotta.

GUILLÉN, Claudio (1998): "El sol de los desterrados: literatura y exilio", en Múltiples moradas, pp. 29-97. Barcelona: Tusquets.

HEIDEGGER, Martin (2002): De camino al habla. Barcelona: Ediciones del Serbal.

JABÈS, Edmond (1976): Le livre des ressemblances. París: Gallimard.

- (1984): Le livre des marges, II. Dans la double dépendance du dit. Montpellier: Fata Morgana.

- (1987): Le livre du partage. París: Gallimard.

- (1989): Un étranger avec, sous le bras, un livre de petit format. Paris: Gallimard.

- (1991): Le livre de l'hospitalité. París: Gallimard.

- (2000): Del desierto al libro. Entrevista con Marcel Cohen. Madrid: Trotta.

- (2003): Le Seuil. Le Sable. Poésies complètes 1943-1988. París: Gallimard.

LAENEN, J. H. (2006): La mística judía. Una introducción. Madrid: Trotta.

LEVINAS, Emmanuel (2006): Totalidad e infinito. Salamanca: Sígueme.

MARTÍNEZ-FALERO, Luis (2009): "El Libro como mito de la modernidad literaria", en Francisco García Jurado, Margit Raders y Juan F. Villar Dégano (eds.), Claudio Guillén: lecciones de un maestro, pp. 189-209. Madrid: Editorial Complutense.

RICCEUR, Paul (1996): Sí mismo como otro. Madrid: Siglo XXI.

SACHS, Nelly (2009): Viaje a la transparencia. Obra poética completa. Edición bilingüe de José Luis Reina Palazón. Madrid: Trotta.

SCHOLEM, Gershom (2000): Las grandes tendencias de la mística judía. Madrid: Siruela. SZONDI, Peter (2005): Estudios sobre Celan. Madrid: Trotta.

VALENTE, José Ángel (2002): Cuaderno de versiones. Barcelona: Galaxia Gutenberg. 